\title{
Cloud-resolving simulation of heavy snowfalls in Japan for late December 2005: application of ocean data assimilation to a snow disaster
}

\author{
M. Yamamoto ${ }^{1}$, T. Ohigashi ${ }^{2}$, K. Tsuboki ${ }^{2}$, and N. Hirose ${ }^{1}$ \\ ${ }^{1}$ Research Institute for Applied Mechanics, Kyushu University, 6-1 Kasuga-kouen, Kasuga 816-8580, Japan \\ ${ }^{2}$ Hydrospheric Atmospheric Research Center, Nagoya University, Furo-cho, Chikusa-ku, Nagoya 464-8601, Japan
}

Received: 25 April 2011 - Revised: 22 July 2011 - Accepted: 1 August 2011 - Published: 26 September 2011

\begin{abstract}
We applied eddy-resolving ocean data assimilation to a cloud-resolving atmospheric simulation of a snow disaster and investigated the effects of mesoscale eddies on a heavy snowfall event in late December 2005. Ocean circulation model (OCM) data assimilation reproduces mesoscale sea surface temperature (SST) structures, which are smoothed out by optimum interpolation. This difference between OCM-assimilation and optimuminterpolation SSTs affects the atmospheric boundary layers over oceanic mesoscale eddies. The atmospheric response to the SST difference is complex at the cold tongue in the central Sea of Japan. Although the horizontal wind and turbulent mixing are quickly and locally affected by the low SST, the atmospheric temperature and water amounts are greatly affected by the upstream high SST via the northwesterly advection. In the heavy snowfall areas, the OCM assimilation greatly affects 10-day accumulated precipitation, though it does not largely influence 10-day mean vertical structures of wind, temperature and water vapor. Thus, we should recognize the significance of oceanic mesoscale eddies for heavy snowfall.
\end{abstract}

\section{Introduction}

Heavy precipitation and severe weather often occur around semi-closed oceans (e.g., the Mediterranean Sea and Sea of Japan) and their neighboring marginal seas. Regional and mesoscale atmospheric models are used for severe weather cases around the East Asian marginal seas (e.g., Kato and Gonda, 2001; Heo and Ha, 2008; Lee and Ryu, 2010; Yamamoto 2011) and the Mediterranean area (e.g., Jansa et al.,

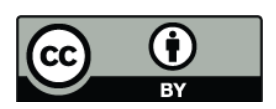

Correspondence to: M. Yamamoto (yamakatu@ riam.kyushu-u.ac.jp)
2000; Davolio et al., 2009). Although sensitivities of the simulations to physical parameterization and sea surface temperature (SST) have been investigated (e.g., Kwun et al., 2009; Gomez et al., 2011; Katsafados et al., 2011), the influences of the mesoscale ocean processes on severe weather are not fully understood.

The Sea of Japan is an important heat and moisture source of heavy snowfall in coastal areas. In particular, the Tsushima Warm Current in the southern Sea of Japan supplies much moisture and heat to the wintertime monsoon and cold-air outbreaks that blow toward Japan (e.g., Manabe, 1957). Recently, satellite measurements have shown that the subpolar front formed by the warm current affects the surface wind and atmospheric boundary layer (Shimada and Kawamura, 2006; 2008). The dynamics of the Tsushima Warm Current determine the surface temperature distribution in the semi-closed Sea of Japan, where there are mesoscale oceanic eddies near the subpolar front and the coastal area. The SST distribution resulting from oceanic processes can modify the dry and cold air mass transported from the Eurasian continent via the upward heat and moisture fluxes over the sea (such a modification is termed air-mass transformation). During a cold air outbreak, this process can cause heavy snowfall in the coastal area. However, because there are serious issues for high-resolution measurement of the SST in cloudcovered marginal seas, we do not fully understand the effect of oceanic mesoscale eddy dynamics on the atmospheric boundary layer and heavy snowfall.

Because of its low resolution, low-frequency microwave imagery with a wide instantaneous field of view cannot avoid missing data along the coasts of marginal seas. In addition, long-term cloud cover is problematic for infrared observation over wintertime marginal seas. Thus, temporal and spatial optimum interpolation is employed for the daily SST estimates to replace missing data. However, this interpolation smoothes the high-resolution SST structures resulting

Published by Copernicus Publications on behalf of the European Geosciences Union. 
from oceanic mesoscale eddies. Recently, the surface temperature of the Sea of Japan has been estimated by combining satellite measurements of the SST and sea surface height (SSH) with an eddy-resolving ocean circulation model (Manda et al., 2005; Hirose et al., 2007). The SST estimated by the assimilation with the ocean circulation model (hereafter, the OCM-assimilation SST) reveals the fine structures of oceanic processes, such as oceanic fronts and eddies, which are masked by cloud and precipitation over a large part of the Sea of Japan. The assimilation SST agrees well with in situ measurements (Hirose et al., 2007). Compared with the smoothed SST data before the assimilation, fine structures of SST are improved by the eddy-resolving OCM assimilation. A significant difference between the optimum-interpolation and OCM-assimilation SST products is observed in the warm core and the cold tongue, where there are obvious fine structures in the OCM-assimilation SST that are smoothed in the optimum interpolation SST. These mesoscale SST structures are persistent during the cold season.

For a developing extratropical cyclone and cold-air outbreak over the Sea of Japan (Yamamoto and Hirose, 2007; 2008) and monthly precipitation in Japan (Yamamoto and Hirose, 2009), the eddy-resolving OCM assimilation improves the weather simulations with horizontal resolution of $10 \mathrm{~km}$. Although we have previously discussed the meteorological effects of mesoscale oceanic processes for a few cases, we have not explained their dynamic influences on heavy snowfall, such as those leading to the weather hazard in the winter of 2005/2006 in Japan (Sato, 2006). Lee and Ryu (2010) applied a satellite-based SST dataset to a heavy snowfall event in Korea. In the present study, using heat and moisture budget analyses we focused on the meteorological effect of the eddy-resolving ocean process in the OCM for modeling a particular event that occurred in late December 2005.

We applied the eddy-resolving ocean data assimilation to a cloud-resolving atmospheric simulation of a snow disaster, and investigated influences of the ocean data assimilation. Technical issues concerning the resolution and interpolation of sea surface measurements could greatly affect the meteorological simulation of heavy snowfall. However, we have yet to investigate the impacts of the oceanic mesoscale eddies, which are smoothed out by optimum interpolation, on the heavy snowfall process. Thus, we conducted atmospheric simulations using both the optimum-interpolation and OCMassimilation SSTs (Sect. 2) and discuss effects of the eddyresolving ocean assimilation on the modeling of weather in the heavy snowfall event (Sect. 3). Because the long-term accumulation of snowfalls in the winter of 2005/2006 caused more than 100 deaths and major social disruption (including collapse of houses, snow slides, electrical outages, and traffic disturbances), this article focuses on the 10-day accumulated precipitation and its related 10-day mean meteorological elements. The results are summarized in Sect. 4.

\section{Data and model}

A merged SST dataset was obtained from satellite and insitu ocean data by an optimum interpolation carried out at the Japan Meteorological Agency (JMA) (Sakurai et al., 2005). The grid data with $1 / 4^{\circ}$ resolution, which are used by the JMA forecasting system and in meteorological simulations around Japan, are termed JMASST. The assimilation estimates of satellite data were made using a Sea of Japan model of the Research Institute for Applied Mechanics (RIAM), Kyushu University, Japan. The SST was assimilated by nudging with a relaxation time of 3 days, and the SSH was assimilated using a reduced-order Kalman filter (Hirose et al., 2007). The output of SST from the $1 / 12^{\circ}$ ocean assimilation model is termed RIAMSST in this article. This assimilation product provides high-resolution SST data for cloudy areas of the Sea of Japan and is consistent with mesoscale oceanic eddies detected in satellite altimeter observations (Morimoto and Yanagi, 2001).

To examine the influences of the two different Sea of Japan SST datasets, (RIAMSST and JMASST) from 00:00 JST 21 December to 00:00 JST 30 December 2005 (when there were heavy snowfalls in Japan), we used a Cloud Resolving Storm Simulator (CReSS) with $3 \mathrm{~km}$ horizontal resolution and a terrain-following vertical coordinate of 60 layers $(0$ to $14814 \mathrm{~m})$. This model has been developed at the Hydrospheric Atmospheric Research Center, Nagoya University, Japan (Tsuboki and Sakakibara, 2001; 2002), and is used for cold-air outbreaks and snowstorms (Liu et al., 2004; Maesaka et al., 2006; Ohigashi and Tsuboki, 2007).

The model domains below 1,5 and $10 \mathrm{~km}$ comprised 8, 27 and 47 layers, respectively. Thirty-hour simulations were conducted for each day and the last 24-h of output data were used for the analysis period. The experiments are termed Exp. J and Exp. R using daily JMASST and RIAMSST, respectively.

The daily SSTs were constant for the 30-h simulations since SST diurnal variations were very small. The initial and boundary conditions were determined from three-hourly forecast data obtained from the JMA regional spectral model. An explicit microphysics scheme of bulk cold rain processes for six species of water (vapor, cloud, ice, rain, snow and graupel) was used in the CReSS without cumulus parameterization (Tsuboki and Sakakibara, 2002). Subgrid-scale turbulent mixing was parameterized by a 1.5 order closure with a turbulent kinetic energy (TKE) prediction (Tsuboki and Sakakibara, 2001). Surface fluxes of sensible heat, latent heat and net radiation were used for ground temperature prediction. 


\section{Results}

The effects of the eddy-resolving ocean assimilation on the cloud-resolving simulation were investigated using the 10day meteorological fields, because the present work considers oceanic mesoscale eddies that are persistent over the winter season and because the heavy snow accumulated during late December 2005.

\subsection{Horizontal structures of meteorological elements}

Figure 1 shows the horizontal distributions of surface temperature, sensible heat flux and latent heat flux in Exp. R. There is a subpolar front (sharp SST gradient) in the central Sea of Japan, where oceanic mesoscale eddies are predominant (Morimoto and Yanagi, 2001). Since the surface and subsurface oceanic flows of the mesoscale eddies strongly disturb the SST gradient, eddy-induced SST structures are likely to appear around the subpolar front. The warm water spreads northward from the Tsushima Strait $\left(34^{\circ} \mathrm{N}, 129^{\circ} \mathrm{E}\right)$ to the Yamato Seamount $\left(39^{\circ} \mathrm{N}, 135^{\circ} \mathrm{E}\right)$. A cold tongue is found to the east of the Yamato Seamount. Surface latent heat flux (evaporation) is high over the Tsushima Warm Current. In particular, the maxima sensible and latent heat fluxes are located around the Yamato Seamount. These heat fluxes along the cold tongue are lower than those in the adjacent area of the warm current. In the present case, the bathymetry of the Yamato Seamount might influence the supply of heat and moisture from the sea surface via the dynamics of the Tsushima Warm Current.

A difference of more than $1 \mathrm{~K}$ between the two SST distributions is predominant over the Sea of Japan, as shown in the right panel of Fig. 1a. RIAMSST is colder than JMASST east of the Korean Peninsula. In contrast, the temperature bias is more than $1 \mathrm{~K}$ warmer in the northern Sea of Japan for RIAMSST. The difference between RIAMSST and JMASST (RIAMSST minus JMASST) directly affects the upward heat flux from the sea surface. The horizontal differences in the surface sensible and latent heat fluxes are similar to the SST differences. In particular, small-scale patchiness of the heat fluxes results from SST patchiness, which is due to oceanic eddies. We discuss later the influences of these oceanic eddy structures on the atmospheric boundary layer according to analyses of the heat and moisture budgets.

A northwesterly cold-air outbreak, with surface wind speeds in excess of $8 \mathrm{~m} \mathrm{~s}^{-1}$ blowing toward Japan, is apparent in Fig. 2a. The horizontal wind in Exp. $\mathrm{R}$ is stronger than in Exp. J in the northern Sea of Japan, where RIAMSST is greater than JMASST, while it is weaker in the coastal area of the Korean Peninsula, where RIAMSST is less than JMASST.

Precipitation is also affected by the SST differences (Fig. 2b). High precipitation is observed over coastal Japan (Fig. 3). The precipitation shown in Fig. 3 was estimated from the JMA radar and AMeDAS (Automated Meteorolog- ical Data Acquisition System) precipitation-gauge measurements (Makihara et al., 1996), and termed the JMA radar AMeDAS precipitation. The simulated precipitation in both experiments is higher than the radar AMeDAS precipitation in mountain areas. The over-prediction of precipitation was also seen in previous mesoscale simulations (e.g., Yamamoto and Hirose, 2009). Because there are so few precipitation gauges in mountain areas, the radar-AMeDAS estimate cannot be accurately corrected by the gauges. In addition, snowfalls are underestimated in the Japanese heavy snowfall areas, owing to the low catch rate of solid particles (Nakai and Yokoyama 2009). In such a case, the radar-AMeDAS precipitation might be inaccurate as a result of the lack of precipitation gauges and underestimation of snowfalls. Accordingly, it is difficult to accurately estimate the root mean square error (RMSE) from the radar AMeDAS precipitation. In the high-snowfall area (Shimane prefecture to Akita prefecture), the model error estimated from observations made with precipitation gauges is $7 \%$ better in Exp. $\mathrm{R}(64.6 \mathrm{~mm})$ than that in Exp. J $(69.4 \mathrm{~mm})$. The precipitation in Exp. $\mathrm{R}$ is $30 \mathrm{~mm}$ less than that in Exp. J on the southern coast of the Sea of Japan and greater than that in Exp. J in the northern Sea of Japan. Thus, the mesoscale SST anomalies greatly affect meteorological elements (wind, heat and moisture fluxes, and precipitation) near the surface. The negative SST anomalies weaken evaporation along the coasts of Japan and Korea. This lower moisture supply results in negative precipitation anomalies along the coast of the Japanese Islands between about $36^{\circ} \mathrm{N}, 136^{\circ} \mathrm{E}$ and $39^{\circ} \mathrm{N}, 140^{\circ} \mathrm{E}$. By contrast, the warm core in the upstream area (positive SST anomaly around $40^{\circ} \mathrm{N}, 135^{\circ} \mathrm{E}$ ) causes local positive anomalies of precipitation in the islands.

\subsection{Vertical structures of meteorological elements}

The vertical structures of atmospheric dynamics and moisture transport over oceanic mesoscale eddies have not been fully investigated in the literature as yet, although they are important in understanding how oceanic eddies modify the cold-air outbreak and lead to heavy precipitation. The present study investigated vertical structures of dynamics and water quantity in the boundary layer, to describe the evolution of air-masses over oceanic mesoscale eddies. In this article, we focus on the atmospheric structures over three sea areas indicated in Fig. 1: area EK (the east coast of the Korean Peninsula), area NY (north of the Yamato Seamount), and area CT (the tip of the cold tongue). Figure 4 shows the vertical distributions of the wind speed, potential temperature, TKE and the vertical component of wind velocity in area EK $\left(37.0^{\circ} \mathrm{N}-37.5^{\circ} \mathrm{N}, 129.5^{\circ} \mathrm{E}-130.0^{\circ} \mathrm{E}\right)$. Below $500 \mathrm{~m}$, where the lower troposphere is unstable, the wind speed and potential temperature in Exp. $\mathrm{R}$ are lower than those in Exp. J. The TKE, which is maximal at $250 \mathrm{~m}$, is lower in Exp. $\mathrm{R}$ than in Exp. J. The low SST leads to low temperature because of low turbulent surface heat flux, and to low wind speed in 
a Tg_Exp. R

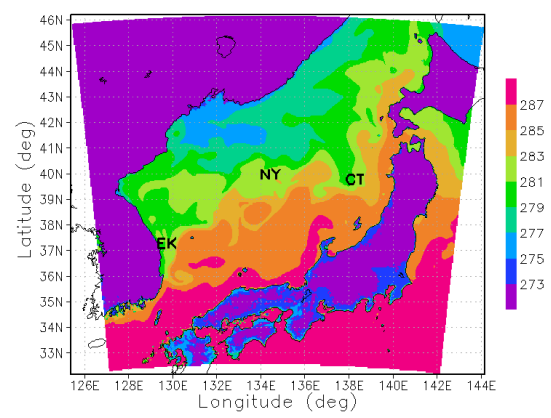

b HS_Exp. R

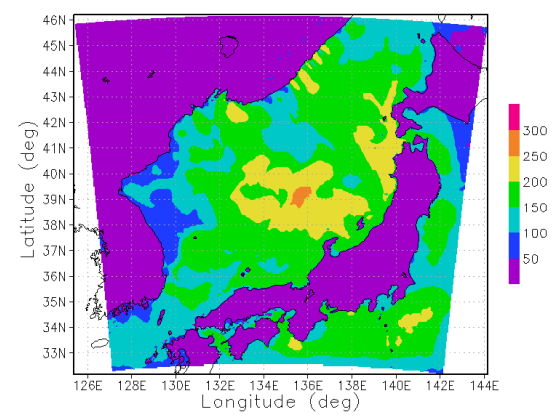

c LE_Exp. R

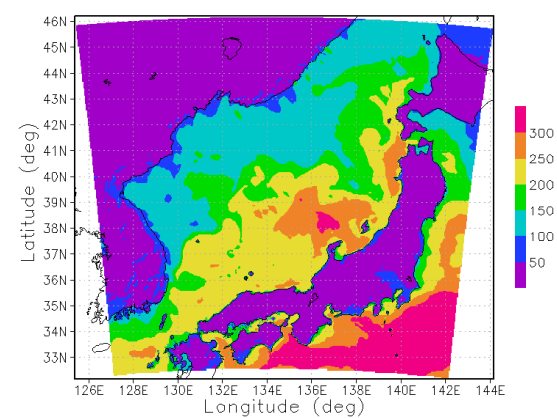

Exp. R-Exp. J

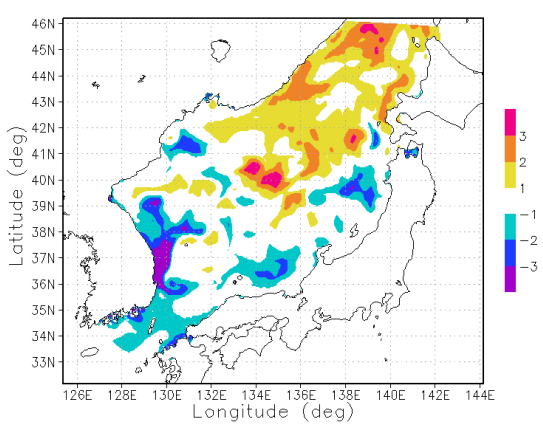

Exp. R-Exp. J

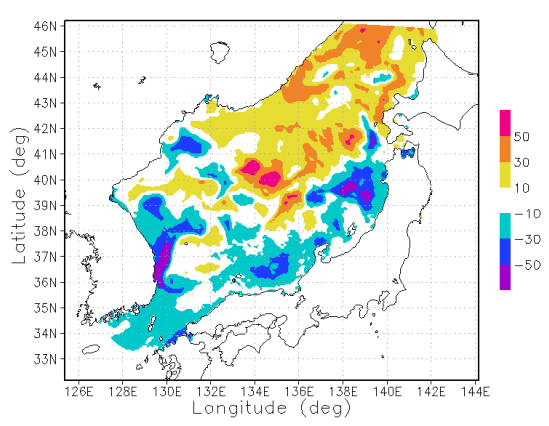

Exp. R-Exp. J

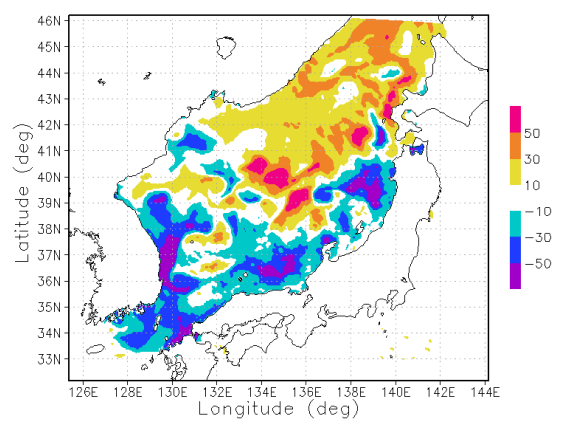

Fig. 1. Horizontal distributions in the Sea of Japan of (a) SST (K), (b) surface sensible heat flux (W m ${ }^{-2}$ ), and (c) surface latent heat flux $\left(\mathrm{W} \mathrm{m}^{-2}\right.$ ) averaged over 21-30 December in Exp. R (left) and their differences between Exp. R and Exp. J (right). EK, NY and CT indicate the east coast of Korea, North Yamato Seamount and the cold tongue.

a situation of little vertical mixing of the strong upper-level wind down to lower levels. The downward vertical velocity, which is capped by the upward motion layer of 2000 to $3000 \mathrm{~m}$, is predominant below $1500 \mathrm{~m}$. The vertical profile in Exp. $\mathbf{J}$ is shifted slightly upward compared with that in Exp. R.

Figure 5 shows the vertical distributions of the water amounts over area EK. Large amounts of water vapor and rain water near the surface rapidly decrease with height. For cloud water (liquid and ice cloud water) and snow water (snow and graupel), the maxima are located at 1400 and $3500 \mathrm{~m}$, respectively. A small amount of water vapor due to low SST results in low levels of cloud water content, snow and rain. The SST anomaly leads to large differences in cloud and snow water between the two experiments, not only in the surface mixed layer (thermally unstable region of 0 to 
a HorizWind_Exp. R

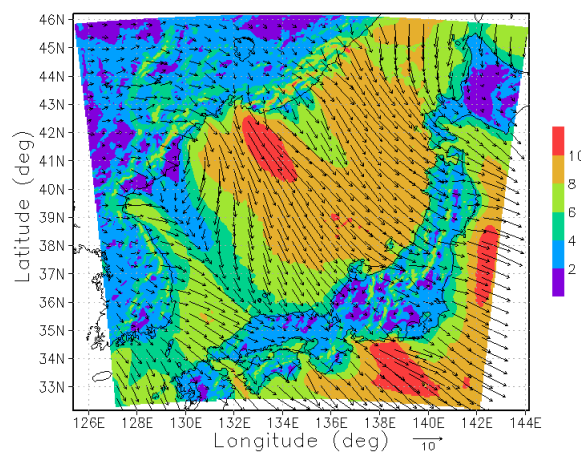

b Precip_Exp. R

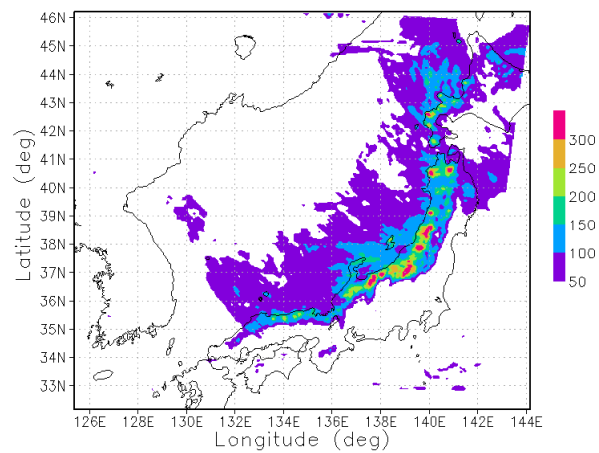

Exp. R-Exp. J

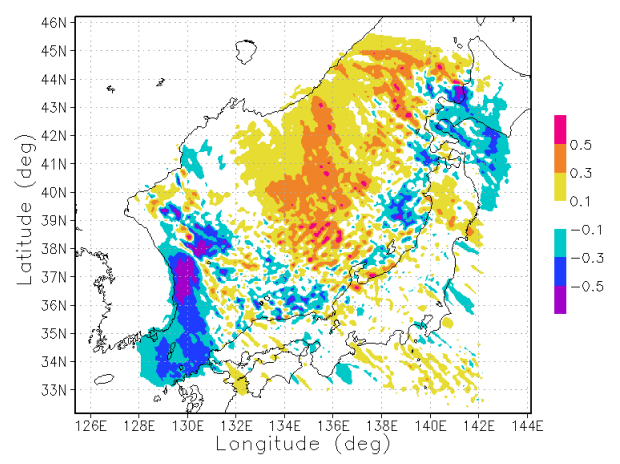

Exp. R-Exp. J

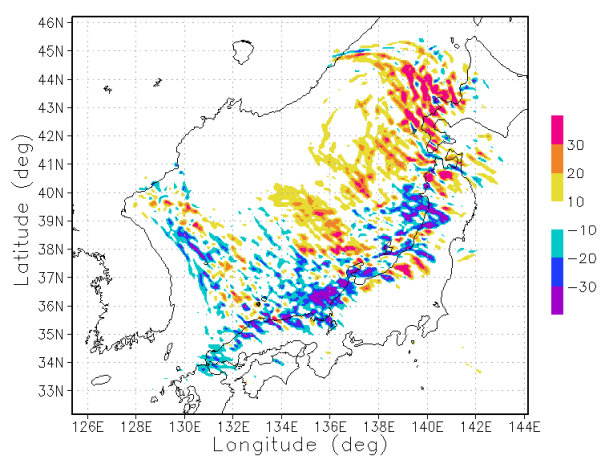

Fig. 2. Horizontal distributions of (a) surface wind $\left(\mathrm{m} \mathrm{s}^{-1}\right.$ ) averaged and (b) precipitation (mm) accumulated over 21-30 December, in Exp. R (left) and their differences between Exp. R and Exp. J. (right)

$500 \mathrm{~m}$ in Fig. 4b), but also above the mixed layer via the enhanced TKE and vertical flow. This indicates that the cloud and snow above the convectively mixed layer are sensitive to the oceanic mesoscale SST anomaly.

Figure 6 indicates the apparent heat and moisture sources calculated from the budget equations:

$Q_{\mathrm{H}}=\frac{\partial \theta}{\partial t}+u \frac{\partial \theta}{\partial x}+v \frac{\partial \theta}{\partial y}+w \frac{\partial \theta}{\partial z}$,

and

$Q_{\mathrm{M}}=\frac{L}{c_{p}}\left(\frac{\partial q}{\partial t}+u \frac{\partial q}{\partial x}+v \frac{\partial q}{\partial y}+w \frac{\partial q}{\partial z}\right)$,

respectively. Here, $t$ is time, $x$ is east-west distance, $y$ is north-south distance, $z$ is vertical distance, $u$ is zonal wind velocity, $v$ is meridional wind velocity, $w$ is vertical wind velocity, $\theta$ is potential temperature, $q$ is mixing ratio of water vapor, $c_{p}$ is the specific heat capacity at constant pressure, and $L$ is the specific latent heat of vaporization. These source terms represent air-mass transformation over the sea. Thus, both $Q_{\mathrm{H}}$ and $Q_{\mathrm{M}}$ have maxima near the surface, and decrease with height. There is air-mass transformation in this region below $700 \mathrm{~m}$, where the TKE is large. Since the turbulent surface heat flux in Exp. $\mathrm{R}$ is less than that in Exp. $\mathrm{J}$, these source terms are also smaller in Exp. R. In summary, low SST leads to weakening of the surface heat flux and horizontal wind and to decreasing of the air temperature, water amount and precipitation.

In the north of the Yamato Seamount (area NY) $\left(39.75^{\circ} \mathrm{N}-\right.$ $40.25^{\circ} \mathrm{N}, 134.25^{\circ} \mathrm{E}-134.75^{\circ} \mathrm{E}$ ), where RIAMSST is higher than JMASST, high SST enhances the horizontal flow and potential temperature below $1000 \mathrm{~m}$ and TKE below $2000 \mathrm{~m}$ (Fig. 7). Downward velocity is predominant in area NY. As opposed to the situation in area EK, there are large differences in the vertical component of velocity above the unstable mixed layer (in the height range of 500 to $2500 \mathrm{~m}$ ). The downward velocity is weaker (the vertical velocity increases in the positive direction) in Exp. R. High SST increases the water amounts of vapor, cloud, snow, and rain, and enhances the heat and moisture sources, as shown in Figs. 8 and 9.

Atmospheric responses in area CT $\left(39.5^{\circ} \mathrm{N}-40.0^{\circ} \mathrm{N}\right.$, $138.0^{\circ} \mathrm{E}-138.5^{\circ} \mathrm{E}$ ) are more complex than those in areas $\mathrm{EK}$ 


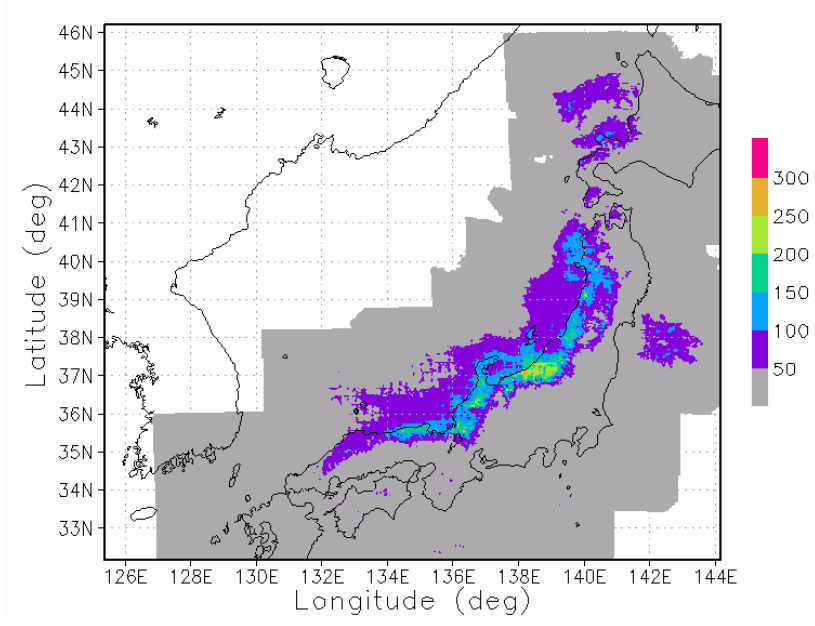

Fig. 3. Horizontal distribution of precipitation ( $\mathrm{mm}$ ) accumulated over 21-30 December, obtained from radar and precipitation gauges (JMA radar AMeDAS). The white areas indicate missing values or areas outside the radar range. a HorizWind

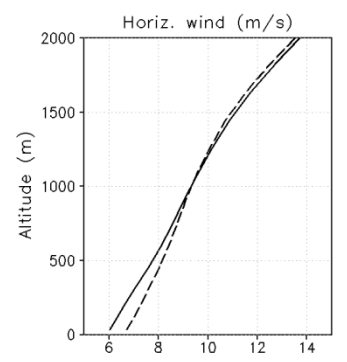

c TKE

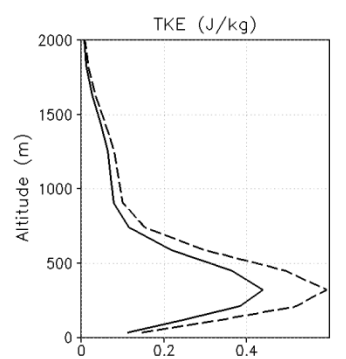

b PotenTemp

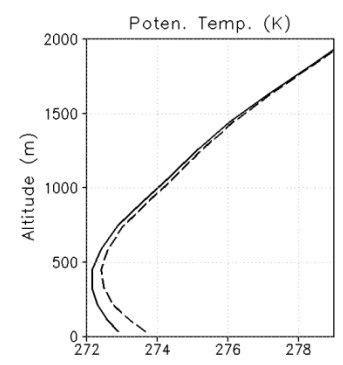

d $\mathrm{W}$

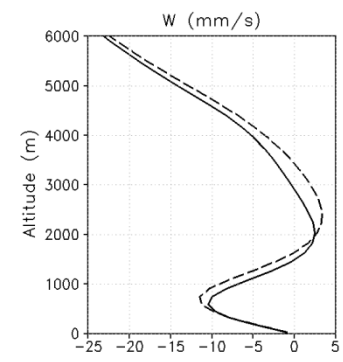

Fig. 4. Vertical distributions of (a) horizontal wind speed $\left(\mathrm{m} \mathrm{s}^{-1}\right)$, (b) potential temperature $(\mathrm{K})$, (c) turbulent kinetic energy $\left(\mathrm{J} \mathrm{kg}^{-1}\right)$, and (d) vertical velocity ( $\mathrm{mm} \mathrm{s}^{-1}$ ) averaged over 21-30 December in area $\mathrm{EK}\left(37.0^{\circ} \mathrm{N}-37.5^{\circ} \mathrm{N}, 129.5^{\circ} \mathrm{E}-130.0^{\circ} \mathrm{E}\right.$ ) for Exp. R (solid line) and Exp. J (dashed line).

and NY. As the air mass moves across the subpolar front, it is strongly modified in the upstream area (the northern Sea of Japan) where RIAMSST is higher than JMASST. In con- a vapor b cloud
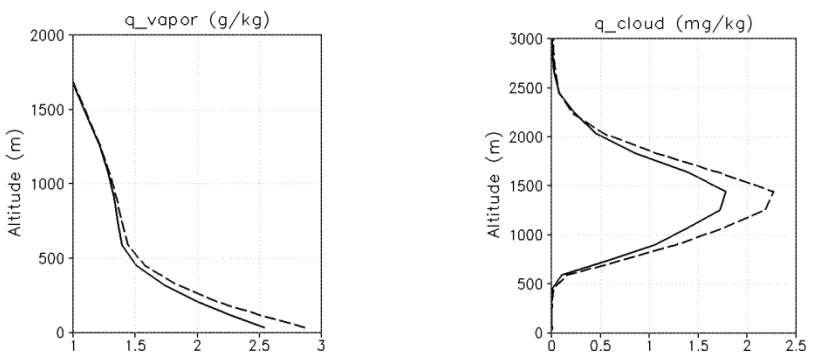

c snow

d rain
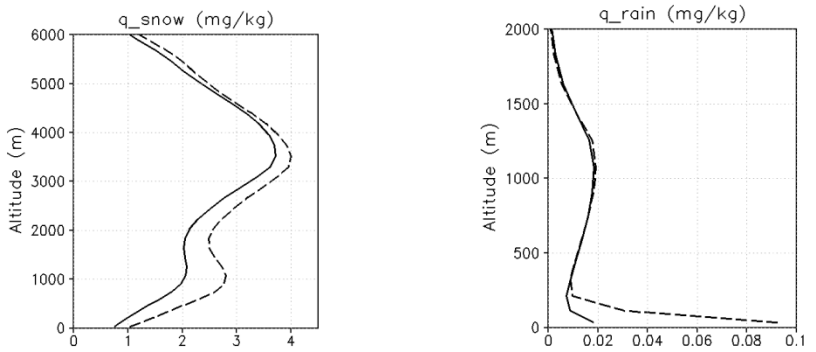

Fig. 5. Vertical distributions of mixing ratios of (a) water vapor ( $g$ $\left.\mathrm{kg}^{-1}\right)$, (b) cloud water $\left(\mathrm{mg} \mathrm{kg}^{-1}\right)$, (c) snow water $\left(\mathrm{mg} \mathrm{kg}^{-1}\right)$ and (d) rain water $\left(\mathrm{mg} \mathrm{kg}^{-1}\right)$ averaged over 21-30 December in area EK $\left(37.0^{\circ} \mathrm{N}-37.5^{\circ} \mathrm{N}, 129.5^{\circ} \mathrm{E}-130.0^{\circ} \mathrm{E}\right)$ for Exp. R (solid line) and Exp. J (dashed line). a $\mathrm{QH}$

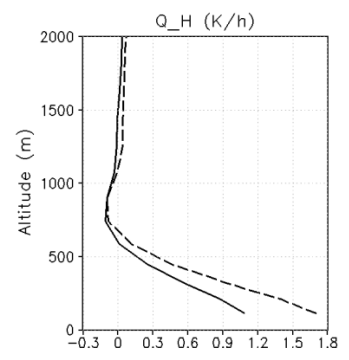

b $\quad \mathrm{QM}$

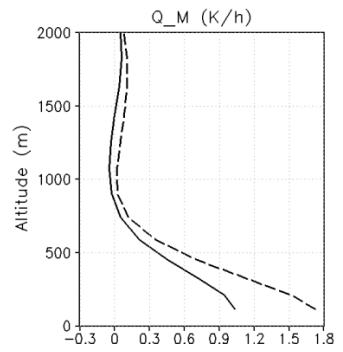

Fig. 6. Vertical distributions of (a) apparent heat source (K hour $\left.{ }^{-1}\right)$ and (b) apparent moisture source $\left(\mathrm{K}_{\text {hour }}{ }^{-1}\right)$ averaged over 2130 December in area EK $\left(37.0^{\circ} \mathrm{N}-37.5^{\circ} \mathrm{N}, 129.5^{\circ} \mathrm{E}-130.0^{\circ} \mathrm{E}\right)$ for Exp. R (solid line) and Exp. J (dashed line).

ditions where high-resolution infrared data are missing because of quasi-stationary cloud cover, the statistical interpolation generally smoothes the SST distribution. In comparison with the interpolation, dynamic ocean data assimilation, which reinforces the sea surface flow with the SSH in the model, is likely to enhance the large-scale SST anomaly contrast across the subpolar front. In short, a positive (negative) SST anomaly is observed upstream (downstream) of the northwesterly wind across the front. In Exp. R, the air 


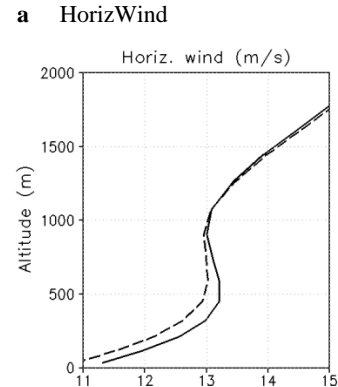

c TKE

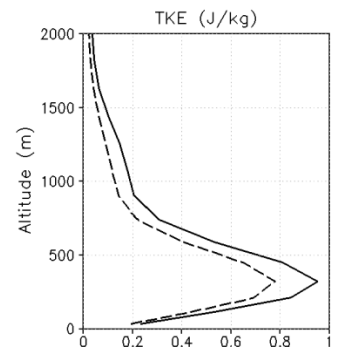

b PotenTemp

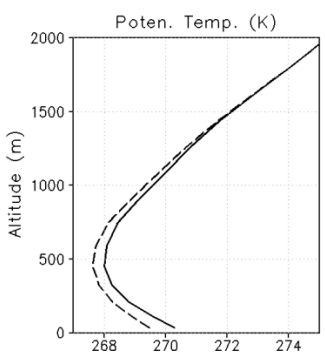

d W

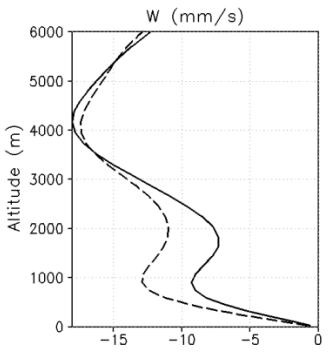

a vapor

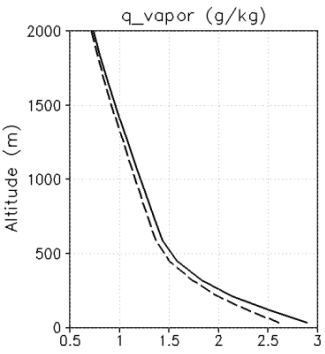

c snow

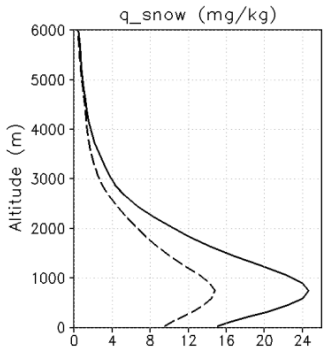

b cloud

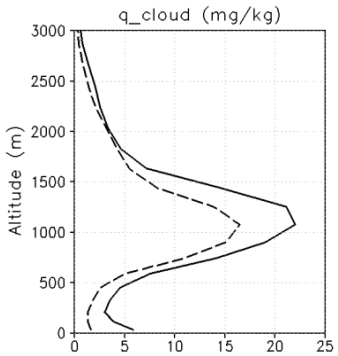

d rain

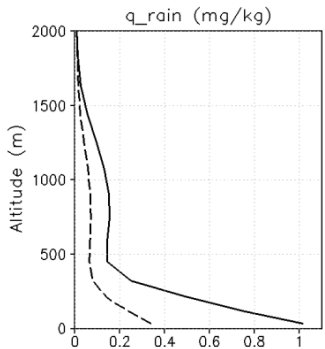

Fig. 7. Vertical distributions of (a) horizontal wind speed $\left(\mathrm{m} \mathrm{s}^{-1}\right)$, (b) potential temperature $(\mathrm{K})$, (c) turbulent kinetic energy $\left(\mathrm{J} \mathrm{kg}^{-1}\right)$, and (d) vertical velocity $\left(\mathrm{mm} \mathrm{s}^{-1}\right)$ averaged over $21-30$ December in area $\mathrm{NY}\left(39.75^{\circ} \mathrm{N}-40.25^{\circ} \mathrm{N}, 134.25^{\circ} \mathrm{E}-134.75^{\circ} \mathrm{E}\right)$ for Exp. $\mathrm{R}$ (solid line) and Exp. J (dashed line).

mass transformed by high SST over the upstream area (the northern side of the subpolar front) is transported by the northwesterly to the tip of the cold tongue (the southern side of the subpolar front).

In such a situation, where the air mass is strongly modified in the upstream sea area, the horizontal wind is weaker and TKE is less in Exp. R than in Exp. J (Fig. 10a and c). This implies that the SST anomaly quickly and locally affects the horizontal wind and turbulent mixing. The potential temperature in Exp. R is higher than that in Exp. J (Fig. 10b) because the temperature increment in the upstream area (RIAMSST higher than JMASST) remains. Upward velocity is predominant in Exp. R (Fig. 10d) at the tip of the cold tongue and this is consistent with the case analysis of the cold-air outbreak around this area by Ninomiya (2006). In contrast, the vertical velocity in Exp. J is downward in the boundary layer. Such sensitivity of the vertical velocity to SST suggests that the sea surface process in the central Sea of Japan greatly affects the formation of upward motion. Thus, a realistic SST estimate is essential for realistically simulating boundary layer dynamics over the Sea of Japan.

The mixing ratios of water vapor below $400 \mathrm{~m}$ and cloud and rain water below $1500 \mathrm{~m}$ in Exp. $\mathrm{R}$ are smaller than those in Exp. J (Fig. 11a, b and d). By contrast, the mixing ratios of water vapor above $400 \mathrm{~m}$ and snow water in Exp. $\mathrm{R}$ are larger than those in Exp. J (Fig. 11a and c). In the situa-

Fig. 8. Vertical distributions of mixing ratios of (a) water vapor ( $\mathrm{g}$ $\left.\mathrm{kg}^{-1}\right)$, (b) cloud water $\left(\mathrm{mg} \mathrm{kg}^{-1}\right)$, (c) snow water $\left(\mathrm{mg} \mathrm{kg}^{-1}\right)$, and (d) rain water $\left(\mathrm{mg} \mathrm{kg}^{-1}\right)$ averaged over 21-30 December in area $\mathrm{NY}\left(39.75^{\circ} \mathrm{N}-40.25^{\circ} \mathrm{N}, 134.25-134.75^{\circ} \mathrm{E}\right)$ for Exp. R (solid line) and Exp. J (dashed line).

a $\mathrm{QH}$

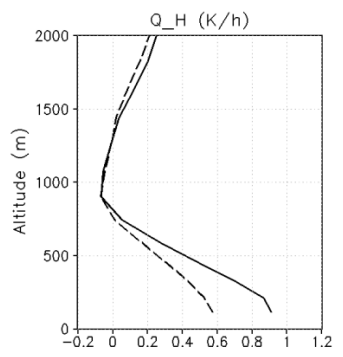

b QM

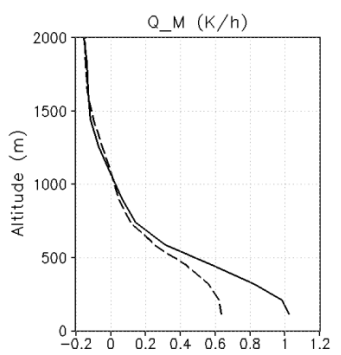

Fig. 9. Vertical distributions of (a) apparent heat source $\left(\mathrm{K} \mathrm{hour}^{-1}\right)$ and (b) apparent moisture source (K hour $\left.{ }^{-1}\right)$ averaged over 21-30 December in area NY $\left(39.75^{\circ} \mathrm{N}-40.25^{\circ} \mathrm{N}, 134.25^{\circ} \mathrm{E}-134.75^{\circ} \mathrm{E}\right)$ for Exp. R (solid line) and Exp. J (dashed line).

tion that the velocity of upward wind is high and the quantity of water vapor is large (as in Exp. R), a high mixing ratio of snow particles might result from the enhanced snow production rate owing to the large amount of water vapor above $500 \mathrm{~m}$, or from the advection of the high snow concentration in the upstream area. Although the heat and moisture sources in Exp. R are weaker than those in Exp. J (Fig. 12), the potential temperature is higher in Exp. R. This indicates that thermal advection from the upstream area dominates the local air-mass transformation. In comparison with the situation 
a HorizWind

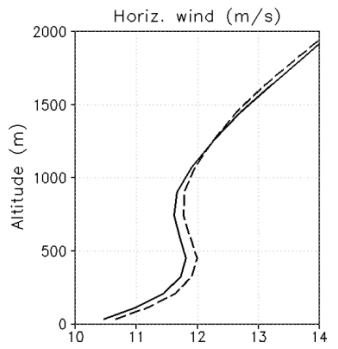

c TKE

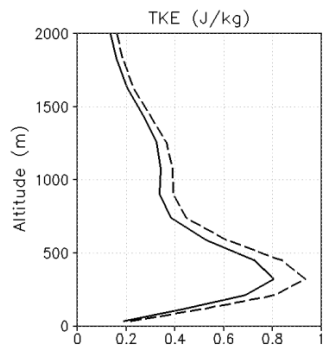

b PotenTemp

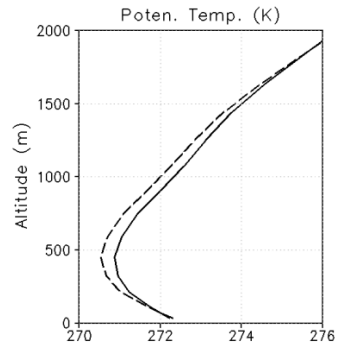

d W

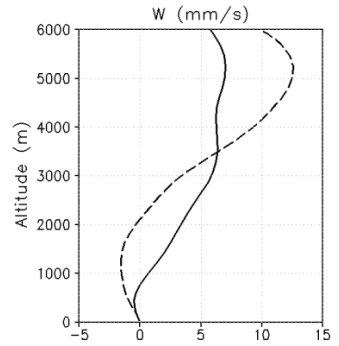

a vapor

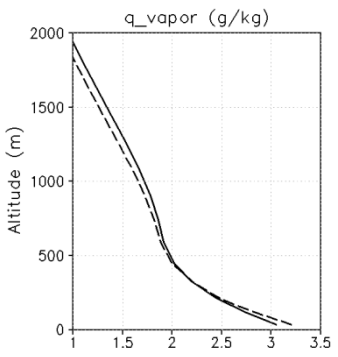

c snow

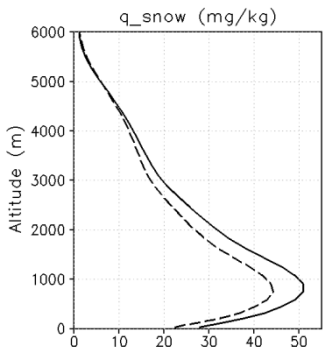

b cloud

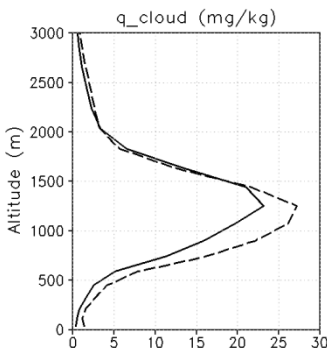

d rain

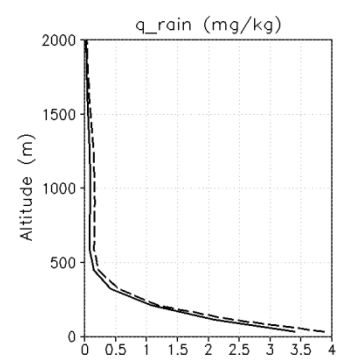

Fig. 10. Vertical distributions of (a) horizontal wind speed $\left(\mathrm{m} \mathrm{s}^{-1}\right)$, (b) potential temperature $(\mathrm{K})$, (c) turbulent kinetic energy $\left(\mathrm{J} \mathrm{kg}^{-1}\right)$, and (d) vertical velocity $\left(\mathrm{mm} \mathrm{s}^{-1}\right)$ averaged over 21-30 December in area $\mathrm{CT}\left(39.5^{\circ} \mathrm{N}-40.0^{\circ} \mathrm{N}, 138.0^{\circ} \mathrm{E}-138.5^{\circ} \mathrm{E}\right.$ ) for Exp. R (solid line) and Exp. J (dashed line).

in Exp. J, there is slightly less water vapor below $400 \mathrm{~m}$ in Exp. $\mathrm{R}$ because of lower surface moisture flux. In contrast, there is more water vapor above $400 \mathrm{~m}$ in Exp. $\mathrm{R}$ because moisture advection from the upstream area is predominant.

Finally, we discuss the vertical atmospheric structures at two coastal upper-air observation sites (Akita and Wajima) in the heavy snowfall area (Fig. 13). It is difficult to compare the simulation with the radiosonde data because of a long sampling time and advection of the balloon near the coastline where the surface conditions rapidly change. For potential temperature, large discrepancies with observations are seen at both sites. The simulated surface layer is unstable, while the observed one is stable. The difference in the static stability influences the vertical distributions of the wind and water vapor. Compared with the observations, the simulated horizontal wind speeds are overestimated below the 900-hPa level, and the simulated mixing ratios of water vapor are overestimated near the surface. In contrast, the simulated potential temperatures and mixing ratios are lower than the observed ones above the 950-hPa level. These discrepancies with observations must be improved in future work to provide accurate forecasting of heavy snowfall.

Differences in the meteorological elements between the two simulations are much smaller than those from the observations on the coastal land, where the differences in ground temperature and surface wind are trivial (Figs. 1 and 2).
Fig. 11. Vertical distributions of mixing ratios of (a) water vapor (g $\left.\mathrm{kg}^{-1}\right)$, (b) cloud water $\left(\mathrm{mg} \mathrm{kg}^{-1}\right)$, (c) snow water $\left(\mathrm{mg} \mathrm{kg}^{-1}\right)$, and (d) rain water $\left(\mathrm{mg} \mathrm{kg}^{-1}\right)$ averaged over 21-30 December in area CT $\left(39.5^{\circ} \mathrm{N}-40.0^{\circ} \mathrm{N}, 138.0^{\circ} \mathrm{E}-138.5^{\circ} \mathrm{E}\right.$ ) for Exp. R (solid line) and Exp. $\mathrm{J}$ (dashed line). a $\mathrm{QH}$

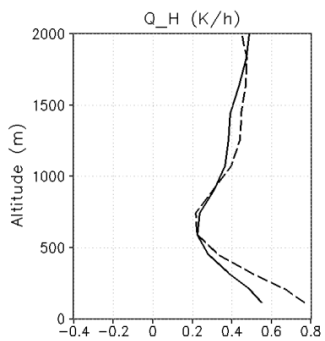

b $\quad \mathrm{QM}$

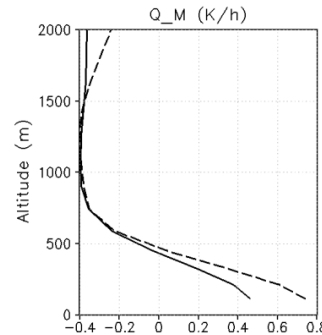

Fig. 12. Vertical distributions of (a) apparent heat source (K hour $^{-1}$ ) and (b) apparent moisture source $\left(\mathrm{K}_{\text {hour }}{ }^{-1}\right)$ averaged over 21-30 December in area CT $\left(39.5^{\circ} \mathrm{N}-40.0^{\circ} \mathrm{N}, 138.0^{\circ} \mathrm{E}-\right.$ $138.5^{\circ} \mathrm{E}$ ) for Exp. R (solid line) and Exp. J (dashed line).

The water vapor at Akita is weakened near the surface by the relatively cold coastal SST in Exp. R, while that at Wajima is enhanced in the region from 950 to $800 \mathrm{hPa}$ by the warm offshore SST. However the differences of the atmospheric structures between the two simulations are small in the coastal area, where large differences in precipitation are found (Fig. 2). This indicates that the meteorological impact of seasonally persistent oceanic mesoscale eddies on the 10-day mean fields is barely apparent in the coastal areas, whereas the impact on the 10-day accumulated 
a Wind
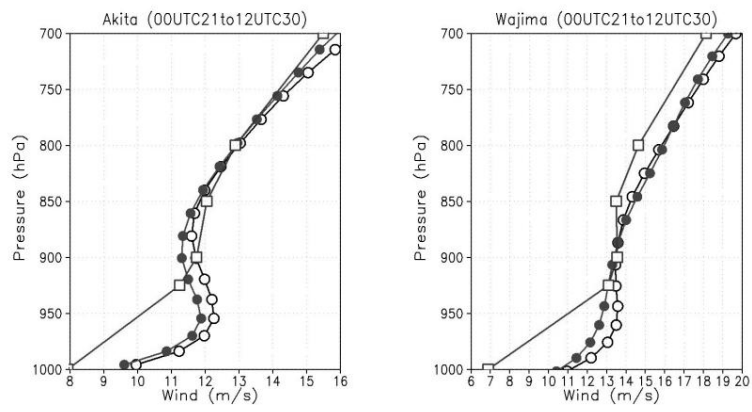

b Potential temperature
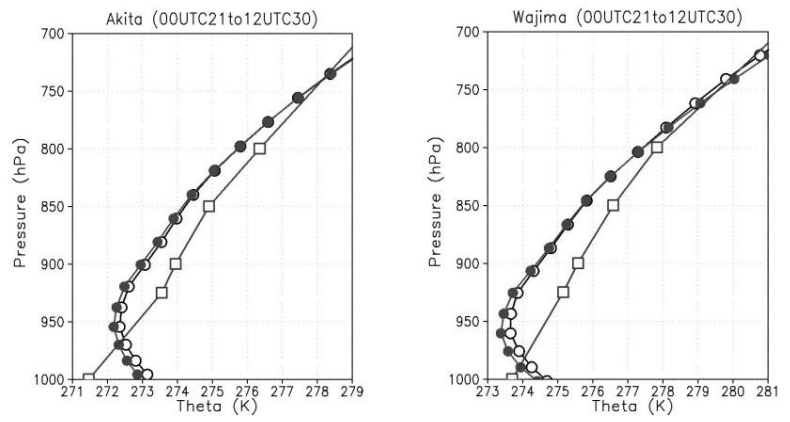

c Water vapor mixing ratio

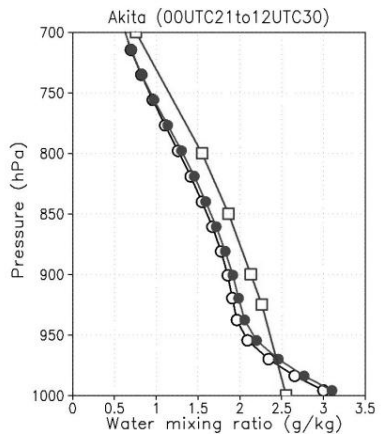

$136^{\circ} \mathrm{E}$ and $39^{\circ} \mathrm{N}, 140^{\circ} \mathrm{E}$. Thus the precipitation weakens in a large part of the Japanese coastal area in Exp. R, owing to the negative SST anomalies. By contrast, the warm core around the Yamato Seamount in Exp. R locally enhances precipitation in the downstream area $\left(37^{\circ} \mathrm{N}, 139^{\circ} \mathrm{E}\right)$. Thus, the long-lived mesoscale eddies strongly influence the 10-day accumulated snowfall. The effects of oceanic mesoscale eddies on the accumulation of precipitation should be examined in the analysis of heavy snowfall.

\section{Concluding remarks}

In this study, we applied eddy-resolving ocean data assimilation to a cloud-resolving simulation of a snow disaster. Dynamic ocean data assimilation using eddy-resolving OCM intensifies meso- and large-scale SST structures in the Sea of Japan, which are smoothed by optimum interpolation because of frequently missing data. As a result, the SST differences between optimum interpolation and OCM assimilation are frequent over the Sea of Japan. Such SST differences would have greatly affected the vertical structures of the atmospheric boundary layer over oceanic mesoscale eddies during the heavy snowfall event in late December 2005. The air-mass transformation below $500 \mathrm{~m}$, forming the unstable surface layer, is sensitive to the sea surface conditions. The sensible and latent heat fluxes, weakened locally by the low SST, reduce the heat and moisture sources in the convectively mixed layer. For the east coast of the Korean Peninsula (area EK), the wind speed, potential temperature, and atmospheric water amounts decrease in Exp. R, owing to a negative SST anomaly that affects surface heat and moisture fluxes. By contrast, north of the Yamato Seamount (area NY), these meteorological elements increase because of a positive SST anomaly. The model results indicate that the SST anomaly resulting from an oceanic mesoscale eddy largely influences the cloud and snow water above the mixed surface layer. However, at the tip of the cold tongue (area $\mathrm{CT}$ ), the sea surface conditions in the upstream area complicate the atmospheric response to the SST, because the thermal and water structures are affected by the high SST in the upstream area via the northwesterly advection.

The OCM assimilation greatly affects the 10-day precipitation around the southern coast of the Sea of Japan, but the vertical structures of the 10-day mean wind, temperature, and water vapor in the coastal observational sites (Akita and Wajima) are much less influenced. Because the OCMassimilation SST is lower than the optimum-interpolation SST along coastal Japan, heavy snowfall prediction in Japan during the snowfall event is somewhat weakened by the OCM assimilation. As a result, the RMSE in Exp. $\mathrm{R}$ $(64.6 \mathrm{~mm})$ estimated using precipitation gauges is $7 \%$ better than that in Exp. J (69.4 mm) in the high-snowfall area. Unfortunately, it is difficult to accurately estimate the error of the observations because of technical issues (the absence of 
precipitation gauges in mountain areas and the wind-induced decrease of catch rate for snow particles); however, a $10 \%$ difference in precipitation between Exp. $\mathrm{R}$ and Exp. $\mathrm{J}$ is significant in the modeling of heavy snowfall. Thus, the mesoscale SST anomalies lead to a large difference in longterm accumulated precipitation. As mentioned above, we should recognize the significance of mesoscale ocean processes on heavy snowfall, specifically the local air-mass transformation over the oceanic mesoscale eddies and the effect of the SSTs on coastal precipitation.

Acknowledgements. This study is a part of the Collaborative Research Program of the Research Institute for Applied Mechanics, Kyushu University and the project "Understanding influences of global warming and rapid economic development on the East Asia marine and atmospheric environment", Kyushu University. This work was partially funded by a Grant-in-Aid for Scientific Research on Innovative Areas (No. 22106003).

Edited by: R. Lasaponara

Reviewed by: C. Holloway and another anonymous referee

\section{References}

Davolio, S., Miglietta, M. M., Moscatello, A., Pacifico, F., Buzzi, A., and Rotunno, R.: Numerical forecast and analysis of a tropical-like cyclone in the Ionian Sea, Nat. Hazards Earth Syst. Sci., 9, 551-562, doi:10.5194/nhess-9-551-2009, 2009.

Gómez, I., Pastor, F., and Estrela, M. J.: Sensitivity of a mesoscale model to different convective parameterization schemes in a heavy rain event, Nat. Hazards Earth Syst. Sci., 11, 343-357, doi:10.5194/nhess-11-343-2011, 2011.

Heo, K. Y. and Ha, K. J.: Snowstorm over the southwestern coast of the Korean Peninsula associated with the development of mesocyclone over the Yellow Sea, Adv. Atmos. Sci., 25, 765-777, 2008.

Hirose, N., Kawamura, H., Lee, H. J., and Yoon, J.-H.: Sequential forecasting of the surface and subsurface conditions in the Japan Sea, J. Oceanogr., 63, 467-481, 2007.

Jansa, A., Genoves, A., and Garcia-Moya, J. A.: Western Mediterranean cyclones and heavy rain. Part 1: Numerical experiment concerning the Piedmont flood case, Meteorol. Appl., 7, 323333, 2000.

Kato, T. and Goda, H.: Formation and maintenance processes of a stationary band-shaped heavy rainfall observed in Niigata on 4 August 1998, J. Meteor. Soc. Japan, 79, 899-924, 2001.

Katsafados, P., Mavromatidis, E., Papadopoulos, A., and Pytharoulis, I.: Numerical simulation of a deep Mediterranean storm and its sensitivity on sea surface temperature, Nat. Hazards Earth Syst. Sci., 11, 1233-1246, doi:10.5194/nhess-11-12332011, 2011.

Kwun, J. H., Kim, Y.-K., Seo, J.-W., Jeong, J. H., and You, S. H.: Sensitivity of MM5 and WRF mesoscale model predictions of surface winds in a typhoon to planetary boundary layer parameterizations, Nat. Hazards, 51, 63-77, 2009.

Lee, S.-H. and Ryu, C.-S.: Influence of continuous satellite-based SST distribution on heavy snowfall events over the Korean Peninsula, Int. J. Remote Sens., 31, 2853-2883, 2010.
Liu, A. Q., Moore, G. W. K., Tsuboki, K., and Renfrew, I. A.: The effect of the sea-ice zone on the development of boundary layer roll clouds during cold air outbreaks, Bound.-Lay. Meteorol., 118, 557-581, 2006.

Maesaka, T., Moore, G. W. K., Liu, A.Q., and Tsuboki, K.: A simulation of a lake effect snowstorm with a cloud resolving numerical model, Geophys. Res. Lett., 33, L20813, doi:10.1029/2006GL026638, 2006.

Makihara, Y., Uekiyo, N., Tabata, A., and Abe, Y.: Accuracy of radar-AMeDAS precipitation, IEICE Trans. Commun., E79-B, 751-762, 1996.

Manabe, S.: On the Modification of air-mass over the Japan Sea when the outburst of cold air predominates, J. Meteor. Soc. Japan, 35, 311-326, 1957.

Manda, A., Hirose, N., and Yanagi, T.: Feasible method for the assimilation of satellite-derived SST with an ocean circulation model, J. Atmos. Ocean. Tech., 22, 746-756, 2005.

Morimoto, A. and Yanagi, T.: Variability of sea surface circulation in the Japan Sea, J. Oceanogr., 57, 1-13, 2001.

Ohigashi, T. and Tsuboki, K.: Shift and intensification processes of the Japan-Sea polar-airmass convergence zone associated with the passage of a mid-tropospheric cold core, J. Meteor. Soc. Japan, 85, 633-662, 2007.

Ninomiya, K.: Features of the polar air outbreak and the energy balance in the transformed air-mass observed over the Japan Sea, J. Meteor. Soc. Japan, 84, 529-542, 2006.

Nakai, S. and Yokoyama, K.: The Importance of the correction of wind-induced undercatch of the gauges: the necessity for compilation of metadata on the gauges, Tenki, 56, 69-74, 2009 (in Japanese).

Sakurai, T., Kurihara, Y., and Kuragano, T.: Merged satellite and in-situ data global daily SST, Geoscience and Remote Sensing Symposium, 2005. IGARSS '05. Proceedings. 2005 IEEE International, 4, 2606-2608, 2005.

Sato, A: Heavy snow fall disaster in the winter of 2005-2006, Shizen Saizai Kagaku, 25, 71-81, 2006 (in Japanese).

Shimada, T. and Kawamura, H.: Satellite observations of sea surface temperature and sea surface wind coupling in the Japan Sea, J. Geophys. Res., 111, C08010, doi:10.1029/2005JC003345, 2006.

Shimada, T. and Kawamura, H.: Satellite evidence of wintertime atmospheric boundary layer responses to multiple SST fronts in the Japan Sea, Geophys. Res. Lett., 35, L23602, doi:10.1029/2008GL035810, 2008.

Tsuboki, K. and Sakakibara, A.: CReSS user's guide, 2nd ed., 210 pp., 2001 (in Japanese).

Tsuboki, K. and Sakakibara, A.: Large-scale parallel computing of cloud resolving storm simulator. in: High Performance Computing. edited by: Zima, H. P., Joe, K., Sato, M., Seo, Y., and Shimasaki, M., Springer, Heidelberg, 243-259, 2002.

Yamamoto, M.: Rapid merger and recyclogenesis of twin extratropical cyclones leading to heavy precipitation around Japan on 9-10 October 2001, Meteorol. Appl., 18, doi:10.1002/met.255, 2011.

Yamamoto, M. and Hirose, N.: Impact of SST reanalyzed using OGCM on weather simulation: A case of a developing cyclone in the Japan-Sea area, Geophys. Res. Lett., 34, L05808, doi:10.1029/2006GL028386, 2007. 
Yamamoto, M. and Hirose, N.: Influence of assimilated SST on regional atmospheric simulation: A case of a cold-air outbreak over the Japan Sea, Atmos. Sci. Lett., 9, 13-17, 2008.
Yamamoto, M. and Hirose, N.: Regional atmospheric simulation of monthly precipitation using high-resolution SST obtained from an ocean assimilation model: Application to the wintertime Japan Sea, Mon. Weather Rev., 137, 2164-2174, 2009. 